\title{
Comunicação e sociabilidade no metrô de Paris: aspectos de um regime de interfaces ${ }^{1}$
}

\section{Janice Caiafa}

\section{Resumo}

Consideramos o metrô como um meio ambiente marcado por um forte componente tecnológico e como um medium, por onde circulam mensagens e pessoas. Com esta inspiração e através de pesquisa etnográfica, apresentamos alguns resultados do trabalho sobre as linhas automáticas (sem condutor humano) do metrô de Paris, que teve 0 apoio da CAPES. Com a automatização, há uma reconfiguração do conjunto de interfaces que se estabelecem no dia a dia da operação e das viagens de metrô. Concentramo-nos no limiar particularmente sensível entre 0 trem e a plataforma e examinamos as interfaces que se constroem entre usuários, agentes e maquinismos, e que geram uma sociabilidade característica.

\section{Palavras-Chave}

Processos comunicativos. Sociabilidade. Metrô (Paris).

\section{Janice Caiafa | janicecaiafa@gmail.com}

Doutora em Antropologia pela Cornell University, EUA, e professora do PPGCOM da Escola de Comunicação da Universidade Federal do Rio de Janeiro - UFRJ, Brasil. É poeta e pesquisadora 1B do CNPq.

\section{0 metrô: um meio}

0 metrô constitui um ambiente povoado de máquinas e de humanos que as utilizam, seja como operadores do sistema metroviário ou como passageiros que devem, a todo instante, abordar igualmente os diversos maquinismos para poder viajar. Cunhei a expressão ambiente maquínico (Caiafa, 2013) para caracterizar essa ênfase no componente tecnológico que marca 0 ambiente do metrô.

Trata-se de um ambiente porque o ocupamos, somos cercados por ele e ali atuamos e nos ligamos a seus outros integrantes. Ribeiro e Cavassan (2012) observam que a palavra "ambiente" compõe-se da preposição latina $a m b$ ("ao redor") e do verbo latino ire ("ir"), significando aquilo que vai à volta ou que rodeia. As palavras inglesa "environment" e francesa "environnement" retêm a mesma semântica de "lugar" e "entorno" (les environs = arredores).

A noção de meio, em muitas etimologias e campos semânticos, se aproxima ou mesmo coincide 
com a de ambiente. Lalande (1999) mostra por que caminhos passaram expressões como "meio social" ou "meio físico" (que se alinham com "meio ambiente"). Trata-se do mesmo sentido de "meio interestelar", o qual remonta à época de Newton, e que designava um intermediário entre os astros através do qual estes agiam uns sobre os outros. Estando entre eles, é igualmente o fluido em que todos os corpos estão mergulhados e que constitui, portanto, o seu meio.

Assim como é um meio ambiente maquínico, o metrô é um medium, uma mídia. Ao lado da via histórico-semântica, os dados etnográficos, que também sugerem 0 aspecto de "ambiente", são 0 melhor teste para a afirmação do metrô como meio de comunicação. Outros autores já sugeriram que 0 conceito de comunicação deveria ser expandido para compreender tanto os fluxos semióticos quanto os materiais (Morley, 2011; Lemos, 2009). Assim, o metrô poderia ser tomado como um medium por onde circulam mensagens e pessoas. Consideremos igualmente que as primeiras acepções de comunicação, construídas por sociólogos no século XIX e início do século XX, abrangiam desde gestos até 0 telégrafo e os trens (Mattelard, 1994).
0 objetivo precípuo de um metrô é conduzir pessoas ao longo de um sistema de linhas ou rede. No mesmo golpe, é preciso que nesse meio/ ambiente (que povoamos e com que trocamos e através do qual nos comunicamos) mensagens sejam incessantemente enviadas de máquina a máquina, de humano a máquina e vice-versa. 0 quotidiano do metrô envolve a comunicação constante entre os computadores embarcados, os fixos nas estações, os circuitos de via, os operadores humanos em seus postos e os usuários do sistema que precisam, muitas vezes, abordar máquinas menos complexas para embarcar (como portas automáticas, intercomunicadores, bilheterias automáticas). Os consoles complexos do PCC (Poste de Commande Centralisé ou CCO, Centro de Controle Operacional), sob o comando dos supervisores humanos, supervisionam todos esses contatos e não cessam de enviar relatórios para viabilizar o movimento dos trens e o funcionamento dos equipamentos do metrô. Em um metrô, o movimento constante de mensagens viabiliza sua operação, ao mesmo tempo que os passageiros circulam ao se inserir nesses circuitos comunicacionais de humanos e maquinismos.

Apresento aqui alguns resultados da pesquisa realizada no contexto das linhas automáticas (sem

Este texto foi apresentado no $24^{\circ}$ Encontro da Compós (Associação Nacional de Programas de Pós-Graduação em Comunicação), entre 9 e 12 de junho de 2015 e produzido no âmbito da pesquisa realizada no Centre de Sociologie de I'Innovation (CSI) da École Supérieure des Mines de Paris, com Bolsa Estágio Sênior da CAPES, de agosto de 2013 a agosto de 2014. Agradeço à CAPES e à equipe do CSI, sobretudo a Madeleine Akrich, Alexandre Mallard, Fabien Muniesa, Sayonara Leal, Marcelo Formazin e Catherine Lucas. Sou grata também a René Schérer, Eduardo Viveiros de Castro, Bruno Latour e Antoine Picon. Entre os profissionais da RATP, agradeço especialmente a Edgar Sée, Corinne Schwebbel, Daniel Audoux, Louis Villiers, Jean-Christophe Delprat e Michel Fayolle. Sou muito grata também a Georgia Louge, Philippe Desseroir e Serge Soler, e ainda a Caetano Jannini, do Metrô de São Paulo, a Mauricio Dimitrov, da ViaQuatro, e a Anne Timbert e Adeline Mayeur. 
condutor humano) do metrô de Paris - as Linhas 1 e 14 -, em que considero o metrô um meio, na rica acepção que procurei apontar anteriormente. Através de pesquisa etnográfica - envolvendo observação participante e conversas com usuários, agentes e membros da diretoria da RATP (Régie Autonome des Transports Parisiens), empresa pública operadora -, examino a introdução dessa inovação tecnológica no sistema parisiense, explorando suas consequências comunicacionais.

Evoco também, pontualmente, minha pesquisa sobre a reconfiguração dos circuitos comunicacionais na Linha 4-Amarela do metrô de São Paulo, primeira linha de metrô automático da América Latina e cujo projeto foi inspirado na experiência de automatização integral da condução do metrô de Paris. ${ }^{2} 0$ trabalho nas duas pesquisas vem constituindo o que Marcus (1998) denominou etnografia multisited (multissituada), em que o pesquisador trabalha em mais de um fieldsite. 0s metrôs do mundo partilham um tipo de tecnologia e uma noção de movimento que justificam a pertinência dessa abordagem especialmente no caso dos metrôs de Paris e de São Paulo, que trocas efetivas reuniram.

\section{Um conjunto de interfaces}

Cada vez mais as tarefas da operação dos metrôs são automatizadas, ou seja, legadas à agência das máquinas. 0 edifício do metrô se povoa de automatismos (escadas, portas, bilheterias) e também é dito "inteligente". A movimentação dos trens tende a ser, nos metrôs do mundo em geral, também parcialmente automatizada.

Na maioria dos metrôs, predomina a modalidade de condução dos trens denominada Piloto Automático, em que o equipamento embarcado conduz o trem e o piloto humano se encarrega de abrir e fechar as portas (e dar a partida em alguns casos), além da importante tarefa de assumir o controle no caso de falha da máquina. Com a entrada definitiva do digital na tecnologia metroviária, os anos 1980 trouxeram a implementação de linhas em que a condução dos trens é feita integralmente por máquinas, sem condutor humano. Em alguns casos, um agente pode ser mantido a bordo - deambulando na composição ou em uma cabine - como salvaguarda em emergências (modalidade DTO, Driverless Train Operation). Na modalidade UTO (Unattended Train Operation), não há presença humana no trem, e o controle é feito a distância pelo PCC.

Com a automatização integral da condução, 0 componente tecnológico do ambiente maquínico do metrô é acentuado. Os agentes humanos passam a trabalhar, sobretudo, como supervisores das máquinas, e as tarefas de campo são minimizadas em prol do trabalho a distância a partir do PCC. 
Um metrô funciona através de um conjunto de circuitos comunicacionais em que se geram constantemente interfaces híbridas (envolvendo componentes humanos e maquínicos). A automatização integral da condução, que se faz frequentemente acompanhar da introdução de outros automatismos no edifício do metrô, impõe um funcionamento muito mais preciso dessas interfaces. Constrói-se um verdadeiro imperativo comunicacional nesses circuitos. 0 ambiente maquínico se torna mais exigente (Caiafa, 2013). Trata-se de um Sistema Integrado de Automatismos (Villoutreix, 1990) mais complexo, com tecnologia de ponta e novas exigências apresentadas aos humanos. Na operação do metrô, adquire ainda mais centralidade a gestão de interfaces.

Um novo regime de interfaces se configura em que se tornam requisitos fundamentais tanto a precisão dos encaixes maquínicos quanto a reatividade da agência humana.

Ao explorar fenômenos da ciência e da técnica e, ao mesmo tempo, avançando um pensamento original das dinâmicas sociais em geral -, Bruno Latour (1992) constrói a noção de uma rede ativa de arranjos coletivos entre heterogêneos. Na rede, tanto os componentes humanos quanto os não humanos são definidos como "actantes", desenvolvendo a seu modo uma forma de ação. Nas relações com a técnica, algumas ações são "delegadas", ou atribuídas seja a um actante humano, seja a um não humano, em um processo de "distribuição de competências".
Em um metrô, a automatização incide sobre o processo de delegação, e os circuitos comunicacionais se reconfiguram. As interfaces sociotécnicas se complexificam no novo regime em que o componente maquínico tende a se impor.

Examinaremos a seguir alguns aspectos dessa dinâmica no quotidiano do metrô de Paris. Veremos como, nesse meio sociotécnico afetado pela inovação tecnológica (que traz consigo, como veremos, novas formas de gerir o humano), modalidades comunicativas e sociabilidades características emergem no dia a dia das viagens.

\section{A automação no metrô de Paris}

0 metrô de Paris é um metrô antigo, um dos primeiros do mundo. Sua primeira linha foi inaugurada em julho de 1900. Rapidamente, ao longo das primeiras décadas do século $\mathrm{XX}, 0$ sistema se expandiu, constituindo um conjunto de 13 linhas. Afora a constante expansão dessas linhas na direção das regiões periféricas, a maior novidade foi, em 1998, a inauguração da Linha 14, a primeira linha com condução totalmente automática, resultado do projeto pioneiro Météor (Métro Est Ouest Rapide). Em 2010, realizou-se a primeira conversão de uma linha existente para essa modalidade de condução (uma segunda já está em curso), automatizando-se a Linha 1, a primeira do sistema.

Diretores da RATP, meus interlocutores, me relataram como a implementação da 14 se deu 
no contexto de um processo de "modernização" do sistema que, de fato, teve início em meados dos anos 1980. Autores que escreveram sobre a empresa também enfatizam este ponto (David, 1995; Léfebvre, 1993; Villoutreix, 1990). A inovação tecnológica trouxe consigo, ao mesmo tempo, um novo regime de gestão humana e a reorganização do trabalho do metroviário. É dessa data também que a preocupação com a produtividade passa a orientar as decisões da empresa. Trata-se, em parte, de um processo mundial, e que vem atingindo as empresas públicas francesas (Tixier, 2002).

Tipicamente, 0 trabalho do agente também se torna híbrido. As tarefas básicas de manutenção, operação e segurança tendem a coincidir ou se mesclar, o que se denomina "polivalência". Assim, um agente do metrô de Paris pode fazer trabalho de atendimento ao usuário e também se encarregar da manutenção emergencial de equipamentos. Constatei processo semelhante de polivalência das funções do metroviário na Linha 4-Amarela do sistema paulista (Caiafa, 2015). No metrô de Paris, o regime de gestão humana que acompanhou a automatização é mais característico das linhas automáticas, mas tende a se estender a todo 0 sistema.

Para estas e outras mudanças profundas, foi preciso instalar novas máquinas e sistemas eprocesso mais complexo - preparar e adaptar os humanos. Em outro trabalho (Caiafa, 2014), mostro como o problema da supressão do condutor foi encaminhado de forma engenhosa na empresa - a um só tempo respeitando os desejos dos condutores e neutralizando resistências. 0s condutores das linhas clássicas (não automatizadas) foram, na época da implementação da 14, chamados a ocupar postos de agent de maîtrise (agentes líderes ou supervisores) na linha, desocupando postos de condutores por todo o sistema, os quais foram sendo ocupados pelos condutores dispensados da Linha 1 automatizada. Empresa pública, a RATP não pode efetuar demissões, mas tem suprido as novas tarefas do sistema que se amplia com 0 mesmo efetivo de empregados.

A Linha 14 (Olympiades - Saint Lazare) e a Linha 1 (Château de Vincennes - La Défense) são, em geral, consideradas eficientes pelos usuários com quem conversei. Se essa eficiência decorre da condução automática, é objeto de discussão (diretores e sindicatos podem discordar), mas, em todo caso, a ausência do condutor, esse personagem-chave da cultura ferroviária, não é um eclipse silencioso, trazendo novas aventuras às viagens.

\section{Trem-fantasma}

A supressão do posto do condutor com a automatização não se fez sem que fosse preciso afirmar, no início do processo, que o seu trabalho seria pobre, ou ao menos empobrecido pelo advento dos sistemas de Piloto Automático. Alain Jeux (1997, p. 115), escrevendo sobre o projeto Météor, observa que, em matéria de segurança ferroviária, "o homem permanece o elo fraco". 
Afirma, em seguida, que os dispositivos destinados a controlar o comportamento do condutor e auxiliá-lo em seu trabalho, em resposta aos numerosos acidentes, além de não permitirem uma performance suficientemente eficaz, seriam "mal aceitos" pelos condutores, cujo trabalho ficaria "robotizado" e "desresponsabilizado".

A expressão "elo fraco", assim como os números sobre a superioridade da máquina sobre 0 piloto humano que 0 autor se refere são retirados diretamente de uma nota técnica da direção da empresa ("l'homme restait le maillon faible"), citada em Joseph (2004: 38). Joseph também menciona a ideia de robotização do trabalho do condutor como presente nas formulações dos empreendedores do projeto Météor. Ele mesmo, a certa altura, sugere que os condutores, com a automatização, poderiam, com as novas funções que ocupam, ingressar em uma "cadeia de cooperação", em que entrariam em contato não só com seus colegas no trabalho tornado coletivo, mas com os passageiros, destacados da massa homogênea que ele transportava (Joseph, 2004, p. 49-58).

De fato, o esquema que faz de ex-condutores agents de maîtrise, mencionado anteriormente, lhes confere um posto bastante rico do ponto de vista do quadro das novas atribuições. Não está certo, por outro lado, que os próprios condutores vejam o seu trabalho como empobrecido. Não é assim que 0 ex-condutor e atual agent de maîtrise com quem conversei, Michel, colocou o problema, e tampouco o condutor François. Este último, inclusive, falou de uma "fierté" (orgulho), que caracterizaria a visão que 0 condutor tem de seu trabalho.

Os muitos condutores com quem conversei em São Paulo também discordavam dessa visão. Com efeito, nenhum deles, seja em São Paulo ou em Paris, desaprovava ou parecia relutante em aceitar a introdução dos sistemas de ajuda à condução - presentes na modalidade de condução Piloto Automático, como vimos. 0 que eles recusam é a automatização integral, responsável por seu desaparecimento.

Se 0 argumento da valorização do trabalho do condutor e mesmo do trabalho do agente em geral está presente hoje no discurso que enaltece a automatização no metrô de Paris, não encontrei, nas conversas com membros dos quadros superiores da empresa, a visão do trabalho do condutor como pobre ou robotizado. Esta se encontra deslocada por outras afirmações, entre elas a de que a automatização permitiria um foco maior no cliente, por exemplo. Parece ter sido importante, nos primeiros tempos do projeto de automatização, apresentar assim 0 trabalho do condutor, como se observa atualmente no contexto da automatização no metrô de São Paulo - o qual se encontra em seus inícios e aprendeu com a experiência parisiense. Em Paris, encontrei, entre os meus interlocutores, o reconhecimento da importância do trabalho do condutor, sobretudo em caso de situações imprevistas e acidentes, embora não com a força suficiente para questionar 
a sua supressão. Como afirmou, por exemplo, Louis Villier, que foi diretor da 14:

É um trabalho que parece repetitivo no quotidiano mas que no entretanto necessita de muito conhecimento e um verdadeiro savoir-faire. É um trabalho para o qual eu, como diretor de linha, sou muito exigente porque se trata de um dos atores pilares da segurança ferroviária. E quando tudo vai bem, parece fácil... Mas um condutor é alguém que é justamente utilizado em situações degradadas, complicadas: quando há avarias, a sinalização, consertar 0 trem... é isto que é complicado.

0 condutor desempenha um papel

particularmente importante, por exemplo, no controle da interface plataforma/via, limiar bem conhecido dos passageiros, que 0 franqueiam quotidianamente ao entrarem e saírem do trem. Aqui, ele é figura-chave para intervir em caso de acidentes e para evitá-los. Villoutreix (1990, p. 55) afirma que o principal problema que se coloca com o desaparecimento do condutor é 0 da segurança dessa interface: "a saber, tanto a detecção de pessoas ou de objetos caídos na via ou presentes sob o túnel quanto a gestão securitária dos movimentos de subidas e descidas em estação".

Quanto à eventual presença de pessoas na via e nos túneis, enfrenta-se, de fato, um risco considerável com a automatização integral da condução. 0 trem automático não para quando alguém cai nos trilhos, seja um passageiro que se jogou, caiu por acaso ou foi empurrado (situações que se apresentam nos metrôs mundialmente), seja um técnico de manutenção que trabalhava no túnel e caiu. Por isso, torna-se imperativo que, por exemplo, os consertos só se deem nas horas mortas, quando o metrô está fechado e não há risco de os trens automáticos estarem circulando.

Em conexão com este ponto, evoco o que me contou Corinne Schwebel, responsável pela movimentação dos trens na Linha 14. Ela me explicou que o limite de "parada securitária" (l'arrêt sécuritaire) de um trem com condutor é o final da plataforma. Quando se trata de um trem automático, contudo, este ponto representa apenas uma "parada funcional", pois a segurança manda que se determine uma extensão maior de até 10 metros além da plataforma, sob o túnel. Não há um controle preciso da parada de um trem automático: "le train peut mal s'arrêter" (o trem pode parar mal). É preciso conceder uma margem de segurança maior para 0 trem automático, pois se está, neste caso, menos garantido. São "trensfantasmas", disse ela, me fazendo suspeitar que este poderia ser um apelido brincalhão usado pelo pessoal da linha - aliás, bem adequado para esses trens eficientes, bonitos e acolhedores, mas que, a bem dizer, disparam sem piloto visível.

Para controlar os riscos na interface plataforma/ via (queda de pessoas e objetos, passageiros presos entre as portas dos trens), costuma-se instalar portas de plataforma - não apenas quando se trata de linhas automáticas, mas, no caso destas, devido à ausência do condutor, a medida torna-se indispensável. Em francês, 
diz-se "portes palières" (portas de patamar) ou "façade de quai" (fachada de plataforma). Essas portas abrem e fecham junto com as portas do trem, isolando a plataforma ao separá-la da via e compondo assim uma fachada.

As portas de plataforma da Linha 1 consistem em pares de retângulos de vidro transparente, medindo em torno de 1 metro e 70 centímetros. As da 14 são bem mais altas e têm uma estrutura em arco que se eleva na direção do teto, acompanhando o feitio abobadado das plataformas. Cria-se uma estética majestosa, característica da linha.

Há ocasiões em que os metrôs recorrem a guardiões humanos para gerir o embarque e o desembarque nas plataformas. No metrô de Londres, frequentemente, avistamos um agente na plataforma supervisionando o fluxo de passageiros e anunciando os percursos e eventuais mudanças. No metrô do Rio de Janeiro e no de São Paulo, também não é incomum encontrar agentes que se postam à entrada dos trens, sobretudo em horas de pico. No metrô de Paris, contudo, tanto nas linhas automáticas quanto nas linhas clássicas, não costuma haver agentes vigiando as interfaces sensíveis trens/plataformas, salvo o controle a distância no PCC. Mas essas plataformas cada vez mais automatizadas, onde os intercomunicadores substituem a presença do agente, são cheias de acontecimentos. Veem-se passageiros o tempo todo forçando as portas dos trens para entrar e para sair, o que anima muito as viagens e reclama, por vezes, não só 0 agente em torno do trem, mas também a presença do condutor desaparecido.

\section{0 patamar, 0 condutor e 0 coelho apressado}

Os usuários com quem conversei apreciam as portas de plataforma e identificam seu papel como dispositivo de segurança. Lembram, em geral, 0 problema dos suicídios e, ainda, o risco de ser empurrado. Armelle diz que, nas plataformas em que não há portas, nunca se coloca na beira, só se aproximando quando o trem estacionou. Rémy, a certa altura, chama as portas de plataforma de "cortinas" ("ces rideaux"). De fato, elas envolvem o espaço como cortinas que correm em torno do trem, criando um ambiente. Nem tanto na Linha 1, pois as portas ali são baixas em relação à enorme dimensão do espaço vazio acima delas. $\mathrm{Na}$ Linha 14, se tem mais essa sensação de ambiente composto e fechado. A Linha 4-Amarela do metrô de São Paulo, com as portas altas e a estética apurada, também produz um ambiente quase fechado entre transparências e de aspecto monumental.

Não é incomum que se chame esse conjunto de "elevador horizontal", como faz Villoutreix (1992, p. 55). Ele diz que 0 equipamento assegura à linha "uma perfeita vedação" ("une parfaite étancheitê"). "Estancar" significa vedar, impedir, por exemplo, que um líquido corra. Por outro lado, dependendo das características das portas - eficientes e magníficas que geralmente são - e das situações em que se inscrevem à mercê dos contatos humanos $\mathrm{e}$ 
maquínicos, essa "étancheité" absoluta pode não ser obtida. São os possíveis desencaixes crônicos ou eventuais entre as portas do trem e as do patamar, por exemplo, e, sobretudo, a ação dos passageiros.

Um interlocutor, engenheiro da RATP, me relatou que na 14 o pessoal comenta que tudo daria certo se não fossem os passageiros. Não passa de brincadeira, mas expressa bem os percursos arriscados que os equipamentos técnicos têm que seguir sob a agência humana, além dos ajustes entre as engrenagens das máquinas. Meu interlocutor se referia justamente às portas de plataforma. No metrô de Paris, como observei anteriormente, é muito frequente que passageiros abram à força as duas portas para poder embarcar, além de outras aventuras. Ele falava também, creio, de uma dificuldade que a automatização em geral enfrenta ao subtrair o humano na operação de um sistema que está repleto deles.

0 patamar que se transpõe entre a plataforma e 0 trem é constantemente objeto de preocupação para os operadores dos metrôs em geral, mesmo quando não há portas de plataforma. 0 mecanismo da máquina é ali assertivo (é hora de fechar: entrada ou saída impossíveis) e não há margem - ou há pouca e em um contexto de riscos - para os ajustes humanos de última hora.

No metrô de Paris, encontramos, nas paredes interiores das portas dos trens, um adesivo avisando do perigo de interferir nesse mecanismo. Um coelho ou lebre com pelo cor de rosa, o rosto branco e vestindo um conjunto de blusa e calça comprida amarelo, mete a mão na porta do trem e um borrão amarelo mostra que 0 contato foi violento. 0 texto diz: "Ne mets pas tes mains/sur les portes, tu risques/de te faire pincer très fort" (Não mete tuas mãos/ nas portas, tu te arriscas/a levar um forte beliscão) - em seguida, várias traduções da frase e uma faixa vermelha embaixo. É possível que seja uma lebre porque esta é conhecida por ser boa de corrida. Mas poderia ser um coelho, evocando o coelho de Alice no país das maravilhas, que consultava o relógio todo 0 tempo e corria, se dizendo atrasado. ${ }^{3} 0$ texto se dirige ao passageiro com grande intimidade, chamando-o ' $t u$ ', tratamento que, segundo as convenções praticadas, só pode se substituir ao formal "vous" quando se trata de uma criança ou de alguém próximo.

Sobre 0 vidro das portas de plataforma da Linha 1, também há adesivos avisando sobre o perigo: "Les portes palières/sont automatiques/Ne pas entraver/leur fonctionnement" (As portas de plataforma são automáticas. Não entravar seu funcionamento). Nas portas de plataforma da Linha 14, não há esse tipo de adesivo, o coelho aparece em avisos nas paredes interiores e exteriores dos trens, alertando para que não se interfira no funcionamento de suas portas. 
As portas de plataforma acrescentam mais um obstáculo à pressa do coelho. Elas abrem e fecham em sincronia com as do trem. Só se abrem após o trem estacionar e se fecham antes da sua partida, tudo em uma questão de segundos. Pode-se ficar preso entre a porta do trem e a da plataforma em uma estação em curva, como me explicou um interlocutor. 0 trem é reto e há, efetivamente, um espaço entre elas quando se fecham. Este deve ser 0 pior cenário, que ainda não observei. No quotidiano das viagens se vê muito passageiro aproveitando 0 espaço que ainda resta antes do fechamento total para forçar a entrada. Há várias situações que podem se produzir em consequência.

Justine me contou que já ficou presa nas portas da Linha 14:

Nessa época eu corria para pegar o meu metrô. Agora não faço mais isso porque notei que o metrô passa a cada 3 minutos mas, se você observar bem no metrô, vai ver que há muita, muita gente que corre... Digamos que isso me serviu de lição. Na 14 eu espero sempre.

Se as portas de plataforma estão abertas, 0 trem não parte. Se qualquer coisa bloqueia a porta do trem, ela reabre um pouco e fecha. Se a pessoa não se solta, permanece lá, vai levar 3 golpes. Se a porta fechar 3 vezes, não vai abrir mais e 0 trem não prossegue. Vai ser preciso uma intervenção do PCC. Para as portas de plataforma, não há três chances para interferir no seu funcionamento, segundo me contou um interlocutor, apenas uma, e o PCC tem que intervir. Na prática, tem-se a impressão, como observam vários usuários, que é constantemente possível impedir o funcionamento das portas, entrar (mesmo um pouco esmagado) e seguir viagem normalmente. Mas claro que, por vezes, 0 trem não pode prosseguir e há histórias desse tipo também.

Quando o processo de fechamento vai se iniciar, soa uma campainha. Katherine me contou que, frequentemente, entra correndo no trem nesse momento. Ela se espantou quando lhe disse que se recomenda que justamente não se faça isso e que, afinal, sequer é preciso, já que o próximo trem em um metrô eficiente como o de Paris - virá em pouco tempo.

- Me acontece muito frequentemente quando escuto 0 "biiil!" de me precipitar a toda velocidade.

- E não acontece nada? Nunca?

- Não. Eu já vi muita gente que fica imprensada... na 14, acho. Mas eles são sempre ajudados pelos outros que puxam as portas. Vi também uma pessoa cuja bolsa ficou imprensada. Sobretudo os homens, homens jovens, eles estão sempre lá para abrir as portas. Eles são muito, muito simpáticos. Nunca vi ninguém se machucar. E eu vejo muita gente imprensada.

Em minha experiência no metrô, inclusive nas linhas automáticas, também observo que as pessoas são ajudadas, e é verdade que são homens jovens os mais dispostos a desentalar 0 pessoal preso nas portas. Parece que Katherine tem a convicção de que nenhum mal advém a quem entra em desacordo com as portas justamente por essa ajuda. 
Justine observou que, para ela, o movimento das portas na Linha 14 é muito mais fluido do que na 1. Trata-se de uma sensação que ela experimenta, mas, curiosamente, um engenheiro da RATP me relatou que o modelo de porta de plataforma da Linha 1 não foi considerado satisfatório. Justamente porque são baixas, essas portas não constituem um obstáculo sólido para passageiros mais dispostos, e eles conseguem pular por cima. Assim, parece que nos próximos projetos vai-se preferir algo no estilo das portas da 14 . Em conexão com isso, um outro profissional da empresa me informou que, em uma ocasião, na Linha 1, um rapaz estava embarcando com os pais e estes não conseguiram entrar, só ele embarcou. Imagino que 0 aviso sonoro já estava em curso. Como a porta do trem ainda se encontrava um pouco aberta, naquela fração de segundos 0 filho saiu do trem e saltou por cima da porta de plataforma, que, de fato, não é tão alta, retornando à plataforma para não embarcar sem os pais.

Na 14, um rapaz, ao entrar às pressas também no último minuto, teve 0 seu laptop retido entre as portas do trem e da plataforma. Quando o trem deu a partida, o laptop caiu e desencadeou uma abertura da porta de plataforma. 0 trem então parou. Como resultado, foi preciso a intervenção em campo do pessoal do PCC. 0 passageiro foi interpelado e ele culpava a operação do metrô. Meu interlocutor, profissional da RATP, me contou que explicaram a ele que, se não houvesse entrado às carreiras com 0 alarme já soando, nada daquilo haveria acontecido. Houve uma interrupção do tráfico no sistema, e o laptop estava em frangalhos. Tudo se resolveu com alguma discussão, porém não houve multa, só um PV (processo verbal).

Hoje, o condutor se ocupa menos de dirigir 0 veículo, mas pode interferir no trabalho da máquina e frear quando vê uma pessoa na via ou um objeto. Ele supervisiona a entrada e a saída de passageiros na composição e 0 funcionamento das portas utilizando os monitores que mostram a movimentação nas plataformas e que se colocam na ponta, bem à entrada do túnel. Se há um problema com as portas ou qualquer outro equipamento, ele pode avaliar a gravidade da avaria e, se preciso - em contato com o PCC -, decidir recolher a composição. Ele pode também providenciar socorro ao passageiro. Trata-se, ademais, de uma presença no próprio trem, o que pouparia aos usuários o tempo de espera até que um agente, orientado pela observação remota, chegasse ao local.

Joseph (2004, p. 38) observa que 0 condutor não só tem o trabalho reduzido pelo sistema de Piloto Automático para conduzir o trem, mas o seu contato com os usuários se limita ao anúncio das más notícias. É verdade, mas a boa notícia é sempre aquela que não se nota e que, de fato, também é trazida pelo condutor - ou seja, quando o trem prossegue sem problemas devido justamente a ele, que auxilia, vigia a máquina e intervém para que a situação não fique pior. Mesmo com a redução 
da autonomia humana no esquema Piloto Automático, o conjunto de interfaces com a máquina funciona ainda com a variedade de ideias e comportamentos, característica da agência humana. É interessante notar como esse funcionamento, que o desenvolvimento das tecnologias microeletrônicas e informáticas coloca no passado, pode-se fazer necessário no novo contexto da automatização integral, em alguma medida e em algumas situações.

A irrupção de uma tecnologia está constantemente acompanhada das insistências humanas uma humanidade que pode, inclusive, evocar o acoplamento com outro regime maquínico, aparentemente superado, como aquele do condutor com os maquinismos de sua cabine. A tecnologia não poderia deixar de se inscrever nessa temporalidade complexa. Os problemas atuais e potenciais no patamar plataforma/via não cessam de evocar esses gestos do passado, estipulados em outras interfaces entre o humano e a máquina e trazidos pelo condutor suprimido no novo regime. É o que se constata no corpo a corpo das viagens, assim como no discurso e nas preocupações dos empreendedores.

As portas de plataforma são mais um equipamento que se coloca nesse limiar sensível. São uma grande garantia de segurança e, ao mesmo tempo, um outro mecanismo automático que é preciso gerir. Um Sistema Integrado de Automatismos demanda uma grande vigilância e uma capacidade rápida de reação dos agentes e supervisores que, em geral avisados por mensagens a distância, podem ter que intervir sobre os equipamentos que apresentem problema. As portas de plataforma são um equipamento que requer especial atenção. No metrô de Paris, mesmo o agente de estação (o qual se ocupa, por exemplo, de fornecer informação aos usuários ou da venda de bilhetes) deve, em geral, ser capaz de intervir sobre as portas de plataforma no caso de mau funcionamento. Segundo entendi, é preciso preparar vários ou muitos para fazê-lo.

Por outro lado, com a redução do pessoal nas estações, medida ligada ao imperativo de produtividade da empresa, encontramos apenas um agente em cada uma. Há os agents de maîtrise, porém, por exemplo, na 14 eles são apenas três na linha (alocados em Bercy, Gare de Lyon e Saint Lazare), ou seja, também podem ter que se deslocar, tanto quanto os que estão do PCC, se forem chamados. E este é mais um aspecto interessante do processo de redistribuição de pessoal e reconfiguração dos circuitos comunicativos que a automatização trouxe no metrô de Paris e que no metrô de São Paulo se tentou seguir. Ao mesmo tempo em que na automatização integral da condução subtrai-se necessariamente 0 condutor e instalam-se novos mecanismos automáticos no trem e por todo 0 edifício - os quais precisam ser constantemente vigiados pelos humanos -, o contingente humano é reduzido ao longo da linha no contexto do novo modelo de organização do trabalho. Novas estratégias são criadas para construir a comunicação entre os humanos - muitas vezes, 
remotamente, através das máquinas, via imagem e sonorização. Como não cessei de constatar, na RATP essa construção é criativa e funcional. Entretanto, o paradoxo permanece: os humanos são chamados a vigiar automatismos muito complexos e numerosos e que geram novos riscos; contudo, a sua presença é cada vez mais fantasmática, ela mesma autorizada e mediada por automatismos.

Só conseguimos entender em parte esta configuração convoluta se introduzimos a preocupação com o controle de custos (que, de fato, é parte da iniciativa para melhoria de produtividade em que a RATP, como outras empresas públicas francesas, ingressou). Um processo de automatização costuma implicar um desenho organizacional que, ao mesmo tempo, 0 antecipa como imperativo em vista de objetivos de ordem político-financeira. A tecnologia parece surgir para realizá-lo. A reatividade necessária para a gestão dos muitos novos automatismos e seus perigos tem que se fazer, estranhamente, com a redução da presença humana em campo, embora se construam novas cadeias de relações, à sua maneira também efetivas. Nem tudo pode ser resolvido a distância, e nas novas cadeias se precisa de tempo para materializar um humano in loco que faça face à emergência. Enquanto isso, os imprevistos não cessam de eclodir no corpo a corpo das viagens, além das possíveis falhas da própria máquina, que também é capaz de preparar surpresas.

\section{Um sopro}

No limiar sensível entre trem e plataforma, os automatismos precisam igualmente se colocar em bons termos. Na Linha 14 parisiense, embora seja raro, já aconteceu um desacordo entre as portas, registrado pelo pessoal do PCC. Era noite, me contou esse interlocutor, e não havia movimento de passageiros. 0 trem passou direto, sem parar na estação como deveria. 0 sensor das portas de plataforma foi, então, acionado, e o PCC recebeu um alarme de abertura anormal das portas. Tratava-se de abertura mínima, mas o pouco que as portas se abram já é detectado pelo sensor. Não havia ninguém na plataforma que pudesse ter forçado essa abertura e percebeu-se, então, que havia sido o vento produzido pela passagem em velocidade do trem, sem parar na plataforma.

Um simples vento que 0 movimento do trem produziu, um sopro na passagem do trem moveu as portas de fachada. Não era a presença do trem, erradamente detectada, mas o seu fantasma.

0 conjunto de automatismos no trem e no edifício do metrô produz alguns fantasmas, a começar pelo próprio trem, que se move sem piloto. As presenças são produzidas via imagem e som, por comunicação remota, em painéis e consoles. A presença humana se reconfigura, seja mediada por essas tecnologias, seja redistribuída ao longo dos postos flexibilizados pela nova organização do trabalho e pelo novo regime de gestão. As presenças são reinventadas e 0 estilo 
fantasmático predomina, tanto nos acidentes quanto nos efeitos buscados.

São várias as ocasiões em que se pode observar como, no processo de introdução de uma tecnologia, a recepção e a adaptação às mudanças se dão em um ritmo próprio. Particularmente, quando se trata de um conjunto complexo de automatismos, como no caso dos metrôs automáticos, em que o funcionamento maquínico está tão inextricavelmente ligado à agência humana. Seja o fenômeno de apropriação pelos usuários, como desenvolve Akrich (2006), seja a questão das interfaces maquínicas, ou problemas da organização do trabalho humano, estamos continuamente diante de ajustes, retomadas e outras soluções laterais - mesmo que pequenas e pontuais. Como assinala Antoine Picon (1994), se a história das tecnologias pode se organizar em torno de algumas grandes rupturas, a história cultural é mais indiferente à flecha do tempo.

\section{Dinâmicas da automação}

A automação é um "processo", escreve Villoutreix (1990, p. 17), "um conjunto de fenômenos", acrescenta, em que a adaptação ao existente se constitui em uma contingência expressiva. Temporalidades diversas se imprimem no processo de automatização, decorrentes de "inércias" impostas por estruturas organizacionais e de gestão e também pelos próprios utilizadores da tecnologia. Um Sistema Integrado de Automatismos não integra só máquinas, mas também "papéis e comportamentos sociais".

Latour (1996, p. 258) observa que 0 objeto técnico é "um processo polêmico". 0 "script" ou programa que estipula, além de comportar prescrições contraditórias, pode ser desafiado por "antiprogramas" que circunstâncias em geral e, sobretudo, os utilizadores lhe contrapõem. De fato, o maquinismo, também em alguma medida maleável e, com certeza, à mercê das situações que constrói com os humanos, funciona em situação de constante teste.

Na experiência de automatização no metrô de Paris, o limiar entre trem e plataforma constitui uma interface particularmente sensível em que esses embates podem ser verificados. As exigências do novo regime de interfaces são retomadas, contrariadas e reconstruídas no corpo a corpo dos engates físicos e nos contatos a distância entre maquinismos, agentes e usuários.

No processo de automatização integral da condução, a supressão do condutor não se prova definitivamente operacional. Ao contrário, a sua ausência consegue fazer sombra em eventos os mais quotidianos das viagens de metrô.

As máquinas - eficientes, fascinantes e aparentemente soberanas - mostram uma face de fragilidade que contraria a autoridade conferida tanto por sua natureza prescritiva quanto pela adesão irrestrita que, por vezes, lhes dedicam os humanos, e não só aqueles portadores da inovação. 
Um falso alarme de abertura de porta que não deixa 0 trem chegar, um sopro apenas que engana as portas pesadas, ou as investidas do coelho apressado são aventuras que povoam as interfaces sociotécnicas no meio/ambiente do metrô de Paris.

\section{Referências}

AKRICH, Madeleine. Les utilisateurs, acteurs de l'innovation. In: AKRICH, Madeleine; CALLON, Michel.; LATOUR, Bruno. (Orgs.). Sociologie de la traduction: textes fondateurs. Paris: Presses des Mines, 2006, p. 253-265.

CAIAFA, Janice. Trilhos da cidade: viajar no metrô do Rio de Janeiro. Rio de Janeiro: Editora 7Letras, 2013. . Dinâmicas da experiência de automatização integral da condução no metrô de Paris.

Contemporânea, v. 12, n. 03, set-dez 2014, p. 595-613. . Automação e presença humana na Linha 4-Amarela do metrô de São Paulo. Galáxia, n. 29, junho de 2015, p. 83-95.

DAVID, Albert. RATP: La métamorphose. Paris: InterEditions, 1995.

JEUX, Alain. A nova geração do metrô de Paris. Revista dos Transportes Públicos. ANTP, Ano 19, $1^{\circ}$ trimestre, 1997, p. 113-122.

JOSEPH, Isaac. Météor: Les métamorphoses du métro. Paris: Ed. Economica, 2004.

LALANDE, André. Vocabulário Técnico e Crítico da

Filosofia. São Paulo: Martins Fontes, 1999.

LATOUR, Bruno. Where Are the Missing Masses? The Sociology of a Few Mundane Artifacts. In BIJKER, Wiebe E.; LAW, John. (Orgs.), Shaping technology/ building society: studies in sociotechnical change. Cambridge: The MIT Press, 1992, p. 225-258.
LEFEBVRE, François. Larchitecte dans le métro: La gestion de l'esthétique des projets à la RATP. Rapport de recherche, RATP, NN 82, 1993.

LEMOS, André. Cultura da Mobilidade. Revista FAMECOS, n. 40, dezembro de 2009, p.28-35.

MARCUS, George. Ethnography through the thick and thin. Princeton University Press, 1998.

MATTELARD, Armand. Comunicação-mundo: história das ideias e das estratégias. Petrópolis: Vozes, 1994.

MORLEY, David. Communications and transport: The mobility of information, people and commodities.

Media, Culture \& Society, v. 33, n. 5, 2011, p.743-759. PICON, Antoine. Les dynamismes des techniques. In: L'empire des techniques. Paris: Éditions du Seuil, 1994, p. 25-37.

RIBEIR0, Job Antonio Garcia; CASSAVAN, Osmar. 0 olhar epistemológico sobre 0 vocábulo ambiente: algumas contribuições para pensarmos a ecologia e a educação ambiental. Filosofia e História da Biologia, v. 7, n. 2, 2012, p. 241-261.

TIXIER, Pierre-Éric. La RATP: une modernisation sous contrainte. In Du monopole au marché. TIXIER, P-E (Org.). Paris: Les Éditions de la Découverte, 2002, p. 49-72.

VILLOUTREIX, Frédéric. Modalités d'étude, de conception et d'introduction de systèmes intégrés d'automatismes. 339 f. Tese (Doutorado). École Nationale Supérieure des Mines de Paris, 1990. 


\begin{tabular}{|c|c|}
\hline $\begin{array}{l}\text { Communication and sociability } \\
\text { in the Paris subway: A few Aspects } \\
\text { of a Regime of Interfaces }\end{array}$ & $\begin{array}{l}\text { Comunicación y sociabilidad en el } \\
\text { metro de París: Aspectos de un } \\
\text { regime de interfaces }\end{array}$ \\
\hline $\begin{array}{l}\text { Abstract } \\
\text { We see the subway as an environment with a strong } \\
\text { technological component, and as a medium that } \\
\text { incessantly moves both messages and people. Within } \\
\text { this framework and taking ethnography as method, we } \\
\text { present a few results of the research on the automated } \\
\text { lines (without human conductor) of the Paris subway, } \\
\text { sponsored by CAPES. With automation, the ensemble } \\
\text { of interfaces of the subway environment undergoes a } \\
\text { reconfiguration. Focusing on the particularly sensitive } \\
\text { threshold between the train and the platform, we } \\
\text { examine the interfaces between users/agents/and } \\
\text { machines, and explore how they generate sociability. } \\
\text { Keywords } \\
\text { Communicative Processes. Sociability. Subway (Paris). }\end{array}$ & $\begin{array}{l}\text { Resumen } \\
\text { Consideramos el metro como un ambiente marcado por } \\
\text { un fuerte componente tecnológico y como un medio a } \\
\text { través del cual circulan mensajes y personas. Con esta } \\
\text { inspiración y a través de investigación etnográfica, } \\
\text { presentamos algunos resultados de una investigación } \\
\text { sobre las líneas automáticas (sin conductor humano) } \\
\text { del metro de París, que fue apoyada por la CAPES. } \\
\text { Con la automatización, hay una reconfiguración del } \\
\text { conjunto de interfaces que se establece en el día de la } \\
\text { operación y de los viajes. Nos centramos en el umbral } \\
\text { particularmente sensible entre el tren y la plataforma } \\
\text { y examinamos las interfaces que se construyen entre } \\
\text { los usuarios, agentes y máquinas, y que producen una } \\
\text { sociabilidad característica. } \\
\text { Palabras clave } \\
\text { Procesos comunicativos. Sociabilidad. Metro (Paris). }\end{array}$ \\
\hline
\end{tabular}




\section{Expediente}

A revista E-Compós é a publicação científica em formato eletrônico da Associação Nacional dos Programas de Pós-Graduação em Comunicação (Compós). Lançada em 2004, tem como principal finalidade difundir a produção acadêmica de pesquisadores da área de Comunicação, inseridos em instituições do Brasil e do exterior.

\section{E-COMPÓS I www.e-compos.org.br I E-ISSN 1808-2599}

Revista da Associação Nacional dos Programas de Pós-Graduação em Comunicação.

Brasília, v.18, n.3, set./dez. 2015.

A identificação das edições, a partir de 2008, passa a ser volume anual com três números.

Indexada por Latindex I www.latindex.unam.mx

\section{CONSELHO EDITORIAL}

Alexandre Farbiarz, Universidade Federal Fluminense, Brasil Alexandre Rocha da Silva, Universidade Federal do Rio Grande do Sul, Brasil Ana Carolina Damboriarena Escosteguy, Pontifícia Universidade Católica do Rio Grande do Sul, Brasil

Ana Carolina Rocha Pessôa Temer, Universidade Federal de Goiás, Brasil Ana Regina Barros Rego Leal, Universidade Federal do Piauí, Brasil Andrea França, Pontifícia Universidade Católica do Rio de Janeiro, Brasil André Luiz Martins Lemos, Universidade Federal da Bahia, Brasil Antonio Carlos Hohlfeldt, Pontifícia Universidade Católica do Rio Grande do Sul, Brasil

Arthur Ituassu, Pontifícia Universidade Católica do Rio de Janeiro, Brasil Álvaro Larangeira, Universidade Tuiuti do Paraná, Brasil Ângela Freire Prysthon, Universidade Federal de Pernambuco, Brasil César Geraldo Guimarães, Universidade Federal de Minas Gerais, Brasil Cláudio Novaes Pinto Coelho, Faculdade Cásper Líbero, Brasil Daisi Irmgard Vogel, Universidade Federal de Santa Catarina, Brasil Denize Correa Araujo, Universidade Tuiuti do Paraná, Brasil Eduardo Antonio de Jesus, Pontifícia Universidade Católica de Minas Gerais, Brasil

Daniela Zanetti, Universidade Federal do Espirito Santo, Brasil Eduardo Vicente, Universidade de São Paulo, Brasil Elizabeth Moraes Gonçalves, Universidade Metodista de São Paulo, Brasil Erick Felinto de Oliveira, Universidade do Estado do Rio de Janeiro, Brasil Francisco Elinaldo Teixeira, Universidade Estadual de Campinas, Brasil Francisco Paulo Jamil Almeida Marques, Universidade Federal do Paraná, Brasil

Gabriela Reinaldo, Universidade Federal do Ceará, Brasil Goiamérico Felício Carneiro Santos, Universidade Federal de Goiás, Brasil Gustavo Daudt Fischer, Universidade do Vale do Rio dos Sinos, Brasil Herom Vargas, Universidade Municipal de São Caetano do Sul, Brasil Itania Maria Mota Gomes, Universidade Federal da Bahia, Brasil
Janice Caiafa, Universidade Federal do Rio de Janeiro, Brasil Jiani Adriana Bonin, Universidade do Vale do Rio dos Sinos, Brasil José Afonso da Silva Junior, Universidade Federal de Pernambuco, Brasil José Luiz Aidar Prado, Pontifícia Universidade Católica de São Paulo, Brasil Juçara Gorski Brittes, Universidade Federal de Ouro Preto, Brasil Kati Caetano, Universidade Tuiuti do Paraná, Brasil

Lilian Cristina Monteiro França, Universidade Federal de Sergipe, Brasil Liziane Soares Guazina, Universidade de Brasília, Brasil Luíza Mônica Assis da Silva, Universidade de Caxias do Sul, Brasil Luciana Miranda Costa, Universidade Federal do Pará, Brasil Malena Segura Contrera, Universidade Paulista, Brasil Maria Ogécia Drigo, Universidade de Sorocaba, Brasil Maria Ataide Malcher, Universidade Federal do Pará, Brasil Marcia Tondato, Escola Superior de Propaganda e Marketing, Brasil Marcel Vieira Barreto Silva, Universidade Federal da Paraíba, Brasil Maria Clotilde Perez Rodrigues, Universidade de São Paulo, Brasil Maria das Graças Pinto Coelho, Universidade Federal do Rio Grande do Norte, Brasil

Mauricio Ribeiro da Silva, Universidade Paulista, Brasil

Mauro de Souza Ventura, Universidade Estadual Paulista, Brasil Márcio Souza Gonçalves, Universidade do Estado do Rio de Janeiro, Brasil Micael Maiolino Herschmann, Universidade Federal do Rio de Janeiro, Brasil Mirna Feitoza Pereira, Universidade Federal do Amazonas, Brasil Nísia Martins Rosario, Universidade Federal do Rio Grande do Sul, Brasil Potiguara Mendes Silveira Jr, Universidade Federal de Juiz de Fora, Brasil Regiane Regina Ribeiro, Universidade Federal do Paraná, Brasil Rogério Ferraraz, Universidade Anhembi Morumbi, Brasil Rose Melo Rocha, Escola Superior de Propaganda e Marketing, Brasil Rozinaldo Antonio Miani, Universidade Estadual de Londrina, Brasil Sérgio Luiz Gadini, Universidade Estadual de Ponta Grossa, Brasil Simone Maria Andrade Pereira de Sá, Universidade Federal Fluminense, Brasil Veneza Mayora Ronsini, Universidade Federal de Santa Maria, Brasil Walmir Albuquerque Barbosa, Universidade Federal do Amazonas, Brasil

\section{COMISSÃO EDITORIAL}

Cristiane Freitas Gutfreind

Pontifícia Universidade Católica do Rio Grande do Sul, Brasil

Irene Machado

Universidade de São Paulo, Brasil

\section{CONSULTORES AD HOC}

Claudia Peixoto de Moura, Pontificia Universidade Católica do Rio Grande do Sul, Brasil Francisco Rüdiger, Pontifícia Universidade Católica do Rio Grande do Sul, Brasil Juremir Machado da Silva, Pontifícia Universidade Católica do Rio Grande do Sul, Brasil Maria Aparecida Baccega, Universidade de São Paulo, Brasil

Roberto Tietzmann, Pontifícia Universidade Católica do Rio Grande do Sul, Brasil

\section{EQUIPE TÉCNICA}

ASSISTENTE EDITORIAL I Márcio Zanetti Negrini

REVISÃO DE TEXTOS I Press Revisão

EDITORAÇÃO ELETRÔNICA I Roka Estúdio

CONTATO I revistaecompos@gmail.com
COMPÓS I www.compos.org.br

Associação Nacional dos Programas de Pós-Graduação em Comunicação

Presidente

Edson Fernando Dalmonte

Programa de Pós-Graduação em Comunicação

e Cultura Contemporânea - UFBA

edsondalmonte@uol.com.br

Vice-presidente

Cristiane Freitas Gutfreind

Programa de Pós-Graduação em Comunicação Social - PUC-RS cristianefreitas@pucrs.br

Secretário-Geral

Rogério Ferraraz

Programa de Pós-Graduação em Comunicação

Universidade Anhembi Morumbi

rogerioferraraz@anhembimorumbi.edu.br 